\title{
Carotid endarterectomy compared with angioplasty and stenting: the status of the debate
}

\section{Felipe C. Albuquerque, M.D., George P. Teitelbaum, M.D., Donald W. Larsen, M.D., and Steven L. Giannotta, M.D.}

Department of Neurological Surgery, Los Angeles County and University of Southern California Medical Center, Los Angeles, California

Endarterectomy is the treatment of choice for patients with symptomatic stenosis of the internal carotid artery. Recently, debate has arisen over the potential benefits of endovascular techniques. Although retrospective analyses of angioplasty and stenting procedures suggest comparable clinical efficacy to endarterectomy, prospective evaluation is pending. The authors review the status of the debate and discuss those issues on both sides that are particularly contentious and clinically relevant.

Key Words * carotid endarterectomy * angioplasty * stenting

Atherosclerotic disease of the common carotid artery bifurcation is associated with 20 to $30 \%$ of cerebrovascular accidents.[13,15,27] Stroke is the third leading cause of death in the United States and the most common and disabling neurological disorder among the elderly worldwide.[13,15,27] In light of these public health concerns, research in the last half of this century has been focused on the optimum treatment of carotid artery stenosis. Prospective analyses such as those performed by the North American Symptomatic Carotid Endarterectomy Trial (NASCET), the Asymptomatic Carotid Atherosclerosis Study (ACAS), and the European Carotid Surgery Trial have demonstrated superior reduction in stroke incidence among symptomatic and a select group of asymptomatic patients who undergo carotid endarterectomy (CEA).[17,18,36] In fact, these studies have established CEA as the "gold standard" for the treatment of carotid artery atherosclerosis.

Despite the proven utility of CEA, technical innovations in interventional radiology have renewed debate over the optimum therapy. Percutaneous transluminal angioplasty and stenting (PTAS) is now commonly performed in centers throughout the United States and Europe despite the lack of a prospective, randomized study comparing this modality to CEA. Two ongoing trials, the Carotid Revascularization Endarterectomy versus Stent Trial (CREST) and the Carotid and Vertebral Artery Transluminal Angioplasty Study (CAVATAS), will attempt to address the comparative efficacy of PTAS and CEA. [4,23] Investigators in a number of retrospective PTAS studies have reported comparable results with CEA in terms of stroke and mortality rates. $[1,3,5,14,20,39,42]$ These favorable results seem to 
support at least a limited role for PTAS in the management of specific subsets of patients with carotid artery stenosis. An analysis of the comparative risks and benefits of the two procedures suggests the relative roles of both in the treatment of carotid disease. We review the nature of the debate and its most contentious points.

\section{DISCUSSION}

The most pertinent risks shared by the CEA and PTAS procedures are stroke and death.[32,38] The NASCET found a $5.8 \%$ incidence of perioperative stroke and death among patients who underwent CEA.[36] The ACAS and European Carotid Surgery Trial reported rates of $2.3 \%$ and $7.5 \%$, respectively.[17,18] A recently published review of 2048 PTAS procedures performed worldwide documented a combined stroke and mortality rate of 5.77\%.[46] Although these results suggest that CEA and PTAS are largely equal in terms of procedurally related deficits, the validity of comparisons between different types of clinical studies is suspect.

For example, patients enrolled in the NASCET and ACAS were rigidly screened,[18,36] and those with significant neurological, cardiovascular, and systemic illnesses were excluded, largely because it was believed that these comorbid factors would adversely affect the rate of procedural complications. On the other hand, the majority of reports on PTAS procedures are retrospective and rarely rigorous in their screening criteria.[5,11,20,22,24,33,35,39,43,47] In fact, a significant percentage of patients undergoing PTAS has been denied CEA because of comorbid factors.[33] Although this suggests an advantage of PTAS over CEA, the nonrandomized nature of the PTAS studies also fails to exclude patients who might artificially lower the rate of procedural complications.

One factor to be considered when assessing the relative risks of CEA compared with those of PTAS is that the two procedures differ in terms of applicability to specific patient populations and lesion types. The presence of intraarterial thrombus is a relative contraindication to the performance of PTAS but not to CEA, whereas ulcerated lesions are associated with a higher than average risk in patients who undergo CEA.[33,40,42,43] Lesions of the high cervical carotid artery are easily reached via an endovascular route, but they are difficult to expose in an open surgical fashion. Patients with stenoses secondary to diseases other than atherosclerosis, such as radiation injury and fibromuscular dysplasia, may be better suited to undergo PTAS rather than CEA, whereas the opposite is true for patients with long or multiple stenoses.[1,33] Therefore, those studies that fail to consider these differences a priori and that compare the efficacy of the techniques in only one patient population may fail to elucidate critical differences between the therapies and the clinical scenarios in which they are applied.

Another contentious issue in the debate is the timing of a randomized comparison between the techniques. Proponents of interventional techniques argue that, as a technique, PTAS is in its infancy and will certainly improve with future technological advancements.[14,22,23] Modifications in catheter and stent design, as well as cerebral protection devices such as occlusion balloons and emboli filters, may significantly reduce the rate of PTAS-associated complications.[1,2,9,15,31,32] With the prospect of improved outcomes, proponents of interventional techniques have been wary of immediate comparisons to the established standards of CEA. Proponents of endarterectomy procedures, however, argue that delaying randomized comparison is unethical.[22,24,35] By failing to assess the efficacy of a newer therapy in relation to the standard therapy, PTAS is allowed to evolve as an accepted practice on the basis of retrospective comparisons to historical controls. In addition, they reject the concept of impending technological advancement, arguing that this proposition could be extended ad infinitum and just as 
easily to CEA as to PTAS.[16,22,24,29,35,49]

Perhaps a more salient question is why should PTAS be compared with CEA. Class I evidence, that which is proven in a prospective, randomized assessment with little likelihood of false-negative and false-positive responses, has established CEA as the optimum treatment of carotid artery occlusive disease.[17,18,36] American surgeons perform more than 100,000 CEAs per year and have done so for more than 40 years. [8,21] In his landmark article on clinical research, Freedman[19] argued that medical therapies should undergo randomized, prospective comparison only if there is a lack of consensus among experts as to the optimum therapy for a single disease process. If such "clinical equipoise" exists, the ethics of comparative studies are justifiable, and the results of such trials should definitively resolve the debate over the superior therapeutic modality.[19]

In the case of PTAS compared with CEA, clinical equipoise does not yet exist. The retrospective nature of studies on PTAS precludes definitive analysis of the risks and benefits of the procedure. Moreover, the retrospective assessment of neurological sequelae that is undertaken by cardiologists and neuroradiologists, the two groups performing the vast majority of PTAS procedures, is not comparable to the rigorous pre- and postoperative assessment of NASCET, which has established the clinical efficacy of CEA.[3,14,20,36,39,43,46,47] On the other hand, proponents of interventional techniques argue that because the majority of patients who undergo PTAS would not have qualified for the NASCET on the basis of comorbid factors, the results of PTAS represent a worst-case scenario.[20,39,43,47] They conclude that because these results are comparable to CEA, at least superficially, PTAS should be less risky than CEA in an equivalent patient population. $[20,39,43,47]$ This final assessment is elusive and will be verifiable only when prospective comparison between the techniques is undertaken in a study in which the patients and complications are audited by experts in neurological assessment.

The only way to achieve clinical equilibrium in the interim before publication of the CREST and CAVATAS results is to perform prospective analysis of PTAS in the treatment of select patients who are deemed at high risk from complications of CEA. Such trials would compare the efficacy of PTAS with that of medical therapy or no therapy at all. Patients enrolled would include those with lesions of the high cervical carotid artery, those with contralateral carotid artery occlusion or concomitant coronary artery disease, those with significant systemic illnesses, and those who suffer from symptomatic restenosis after CEA.[1,7,41] In fact, PTAS may prove the most effective means of treating restenosis after primary CEA. $[6,12,34,44]$ In a series in which 25 patients experienced carotid artery restenosis after CEA treated by PTAS, Yadav, et al.,[48] reported no major strokes and only one minor stroke for a total complication rate of $4 \% .[6,12,34,44,48]$ Designing prospective trials to study PTAS based on these suggestive retrospective results successfully circumnavigates the moral dilemma of not performing CEA in all patients with carotid artery stenosis.

The executive committee of CREST has sought to establish clinical equipoise by adopting a number of prerequisites.[23] Most important, prior to becoming enrolled in the study, trial centers will have to demonstrate competence in PTAS by having their surgeons perform 30 procedures in a subset of symptomatic patients who prefer PTAS to CEA.[23] This pretrial phase should soften the arguments of critics on both sides who are dubious about characterizing results that are produced in a multicenter fashion and who fear wide variability in the technical capabilities of the participating centers. On the other hand, CAVATAS has drawn criticism from practitioners who argue that the study fails to establish standardized inclusion and exclusion criteria, leaving such decisions to the participants. $[4,25,35]$ For example, the study protocol advises its members to avoid including patients with intraluminal 
thrombus.[4,25,35] This mandate becomes difficult to enforce when one considers that neither duplex ultrasonography nor digital subtraction angiography can reliably identify intraluminal thrombus. Failure to enforce strict guidelines in any prospective study in which there are attempts to assess the comparative efficacy of PTAS compared with CEA will inevitably draw justifiable protestations from supporters of each technique.

The most daunting problem in mounting prospective, randomized comparisons between PTAS and CEA is the vast number of patients required for enrollment. [3,14,22,23] To establish a clinically significant difference between the two treatments, more than 3000 patients will need to undergo treatment. $[3,14,22,23]$ This number, moreover, fails to take into account the stratification of patients based on comorbid risk factors. To verify a clinical advantage of one therapy over another among particular subgroups, such as those with recurrent stenosis, a significantly larger number of patients is needed. Protracted follow-up studies and careful audits of clinical endpoints, such as major and minor strokes, further complicate the establishment of prospective comparisons between the techniques.[10,26,28,30,33,38,45]

In this era, financial concerns affect the debate over the efficacy of PTAS and CEA as well. Retrospective studies performed by proponents of both sides indicate lower costs for their respective procedure.[25,37] Given the contentious nature of this issue and its impact on the patient population as a whole, prospective analyses should consider cost as a factor of comparison. Monetary issues affect this debate in other ways. More than a dozen American and European companies currently manufacture stents that are in various stages of application and governmental approval [1-3,9]. Percutaneous transluminal angioplasty and stenting as a whole is in its nascency. Therefore, current research is focused on technical advancements, which in turn drive and produce financial gains. The momentum behind these financial and technical influences has helped to popularize the use of PTAS despite the lack of a randomized comparison with CEA.

\section{CONCLUSIONS}

Athough retrospective analysis of PTAS suggests it has practical application in the treatment of patients with carotid artery stenosis, randomized comparison studies to CEA do not exist. The lack of a state of clinical equilibrium between the therapies argues against the performance of a randomized comparison. Nonetheless, successful retrospective studies of PTAS, which suggest comparable morbidity and mortality rates, as well as distinct advantages in specific clinical scenarios, have driven efforts to compare the techniques. This prospective analysis will be complicated by the requirement of a vast number of patients with varying comorbid factors, as well as by the need for prolonged follow-up review by specialists who are trained to perform neurological examination. Prior to the publication of these results, PTAS should be performed only in those patients whose risks in undergoing CEA are excessive. Prospective analysis of this subgroup of patients may hasten or negate the development of clinical equilibrium, or it may suggest other applications of PTAS in the treatment of select cases.

\section{References}

1. Albuquerque FC, Teitelbaum GP, Giannotta SL: The neurosurgical treatment of stroke. Neurol Contin (In press)

2. Becker GJ: Should metallic vascular stents be used to treat cerebrovascular occlusive diseases?

Radiology 191:309-312, 1994 
3. Bettmann MA, Katzen BT, Whisnant J, et al: Carotid stenting and angioplasty: a statement for healthcare professionals from the Councils on Cardiovascular Radiology, Stroke, Cardio-Thoracic and Vascular Surgery, Epidemiology and Prevention, and Clinical Cardiology, American Heart Association. Stroke 29:336-338, 1998

4. Brown MM: Carotid and vertebral artery transluminal angioplasty study (CAVATAS). Stroke 27:358, 1996 (Abstract)

5. Brown MM, Crawley F, Clifton A, et al: Percutaneous transluminal angioplasty of the internal carotid artery. Br J Surg 84:729-730, 1997 (Letter)

6. Callow AD: Recurrent stenosis after carotid endarterectomy. Arch Surg 117:1082-1085, 1982

7. Caplan LR, Skillman J, Ojemann R, et al: Intracerebral hemorrhage following carotid endarterectomy: a hypertensive complication? Stroke 9:457-460, 1978

8. Cebul RD, Snow RJ, Pine R, et al: Indications, outcomes, and provider volumes for carotid endarterectomy. JAMA 279:1282-1287, 1998

9. Chaturvedi S: Medical, surgical, and interventional treatment for carotid artery disease. Clin Neuropharmacol 21:205-214, 1998

10. Chaturvedi S, Femino L: Are carotid endarterectomy complication rates being monitored? Neurology 50:1927-1928, 1998

11. Crawley F, Clifton A, Taylor RS, et al: Symptomatic restenosis after carotid percutaneous transluminal angioplasty. Lancet 352:708-709, 1998 (Letter)

12. Das MB, Hertzer NR, Ratcliff NB, et al: Recurrent carotid stenosis: a five-year series of 65 reoperations. Ann Surg 202:28-35, 1985

13. Donnan GA, Davis SM, Chambers BR, et al: Surgery for prevention of stroke. Lancet 351:1372-1373, 1998

14. Dorros G: Stent-supported carotid angioplasty: should it be done, and, if so, by whom? A 1998 perspective. Circulation 98:927-930, 1998

15. Easton JD: Current advances in the management of stroke. Neurology 51 (Suppl 3):S1-S2, 1998

16. Eckert B, Thie A, Valdueza J, et al: Transcranial doppler sonographic monitoring during percutaneous transluminal angioplasty of the internal carotid artery. Neuroradiology 39:229-234, 1997

17. European Carotid Surgery Trialists' Collaborative Group: MRC European Carotid Surgery Trial: interim results for symptomatic patients with severe (70-99\%) or with mild (0-29\%) carotid stenosis. Lancet 337:1235-1243, 1991

18. Executive Committee for the Asymptomatic Carotid Atherosclerosis Study: Endarterectomy for asymptomatic carotid artery stenosis. JAMA 273:1421-1428, 1995

19. Freedman B: Equipoise and the ethics of clinical research. N Engl J Med 317:141-145, 1987 20. Gil-Peralta A, Mayol A, Marcos JR, et al: Percutaneous transluminal angioplasty of the symptomatic 
atherosclerotic carotid arteries: results, complications, and follow-up. Stroke 27:2271-2273, 1996 21. Hertzer NR, O'Hara PJ, Mascha EJ, et al: Early outcome assessment of 2228 consecutive carotid endarterectomy procedures: the Cleveland Clinic experience from 1989 to 1995. J Vasc Surg 26:1-10, 1997

22. Heuser RR: Success with carotid stenting: a stroke of good luck or the wave of the future? Cathet Cardiovasc Diagn 44:7-8, 1998

23. Hobson RW II, Brott T, Ferguson R, et al: Regarding "Statement regarding carotid angioplasty and stenting." J Vasc Surg 24:1117, 1997 (Letter)

24. Jordan WD Jr, Voellinger DC, Fisher WS, et al: A comparison of carotid angioplasty with stenting versus endarterectomy with regional anesthesia. J Vasc Surg 28:397-403, 199

25. Jordan WD Jr, Roye GD, Fisher WS III, et al: A cost comparison of balloon angioplasty and stenting versus endarterectomy for the treatment of carotid artery stenosis. J Vasc Surg 27:16-24, 1998

26. Kluytmans M, van der Grond J, Eikelboom BC, et al: Long-term hemodynamic effects of carotid endarterectomy. Stroke 29:1567-1572, 1998

27. Kuller LH: Incidence rates of stroke in the eighties: the end of the decline in stroke? Stroke 20:841-843, 1989

28. Lanska DJ, Kryscio RJ: In-hospital mortality following carotid endarterectomy. Neurology 51:440-447, 1998

29. Lineberger CK, Lubarsky DA: Con: general anesthesia and regional anesthesia are equally acceptable choices for carotid endarterectomy. J Cardiothor Vasc Anesth 12:115-117, 1998

30. Manheim LM, Sohn MW, Feinglass J, et al: Hospital vascular surgery volume and procedure mortality rates in California, 1982-1994. J Vasc Surg 28:45-58, 1998

31. Markus HS, Clifton A, Buckenham T, et al: Carotid angioplasty. Detection of embolic signals during and after the procedure. Stroke 25:2403-2406, 1994

32. Markus HS, Clifton A, Buckenham T, et al: Improvement in cerebral hemodynamics after carotid angioplasty. Stroke 27:612-616, 1996

33. Mathur A, Roubin GS, Iyer SS, et al: Predictors of stroke complicating carotid artery stenting. Circulation 97:1239-1245, 1998

34. Meyer FB, Piepgras DG, Sundt TM, et al: Recurrent carotid stenosis, in Meyer FB (ed): Sundt's Occlusive Cerebrovascular Disease, ed 2. Philadelphia: WB Saunders, 1994, pp 310-321

35. Naylor AR, Bolia A, Abbott RJ, et al: Randomized study of carotid angioplasty and stenting versus carotid endarterectomy: a stopped trial. J Vasc Surg 28:326-334, 1998

36. North American Symptomatic Carotid Endarterectomy Trial Collaborators: beneficial effect of carotid endarterectomy in symptomatic patients with high-grade carotid stenosis. N Engl J Med 325:445-453, 1991 
37. Ricotta JJ, Hargadon T: Cost management strategies for carotid endarterectomy. Am J Surg 176:188-192, 1998

38. Rigdon EE: Racial and gender differences in outcome after carotid endarterectomy. Am Surg 64:527-532, 1998

39. Roubin GS, Yadav S, Iyer SS, et al: Carotid stent-supported angioplasty: a neurovascular intervention to prevent stroke. Am J Cardiol 78:8-12, 1996

40. Rothwell PM, Slattery J, Warlow CP: A systematic review of the risks of stroke and death due to endarterectomy for symptomatic carotid stenosis. Stroke 27:260-265, 1996

41. Sundt TM, Sandok BA, Whisnant JP: Carotid endarterectomy. Complications and preoperative assessment of risk. Mayo Clin Proc 50:301-306, 1975

42. Teitelbaum GP, Lefkowitz MA, Giannotta SL: Carotid angioplasty and stenting in high-risk patients. Surg Neurol (In press)

43. Théron JG, Payelle GG, Coskun O, et al: Carotid artery stenosis: treatment with protected balloon angioplasty and stent placement. Radiology 201:627-636, 1996

44. Treiman GS, Jenkins JM, Edwards WH Sr, et al: The evolving surgical management of recurrent carotid stenosis. J Vasc Surg 16:354-363, 1992

45. Wennberg DE, Lucas FL, Birkmeyer JD, et al: Variation in carotid endarterectomy mortality in the Medicare population: trial hospitals, volume, and patient characteristics. JAMA 279:1278-1281, 1998

46. Wholey MH, Wholey M, Bergeron P, et al: Current global status of carotid artery stent placement. Cathet Cardiovasc Diagn: 44:1-6, 1998

47. Yadav JS, Roubin GS, Iyer S, et al: Elective stenting of the extracranial carotid arteries. Circulation 95:376-381, 1997

48. Yadav JS, Roubin GS, King P, et al: Angioplasty and stenting for restenosis after carotid endarterectomy. Initial experience. Stroke 27:2075-2079, 1996

49. Zvara DA: Pro: regional anesthesia is the best technique for carotid endarterectomy. J Cardiothor Vasc Anesth 12:111-114, 1998

Manuscript received November 5, 1998.

Accepted in final form November 12, 1998.

Address reprint requests to: Steven L. Giannotta, M.D., Department of Neurological Surgery, University of Southern California, Los Angeles County and University of Southern California Medical Center, Suite 5046, 1200 North State Street, Los Angeles, California 90033. 